\title{
LUGARES IMAGINÁRIOS EM REDE - NARRATIVAS DE MEMÓRIA EM AMBIENTES PROGRAMÁVEIS
}

\author{
Carlos Henrique Rezende Falci*
}

\begin{abstract}
RESUMO: A memória precisa de um lugar fixo para se estabelecer? A memória precisa de arquivos para existir? E que tipo de arquivos? Embora se possa dizer que a memória talvez nunca tenha se definido a partir de um lugar fixo, penso que o próprio estabelecimento do conceito enquanto tal é marcado pela ideia de um lugar, de um registro em que a memória possa ser encontrada. Mesmo quando ela é associada ao imaginário, ou ao que é instável, há uma tensão associada à busca de um local da/para a memória. O propósito desse artigo é verificar como essa organização que cria a memória, e um lugar no passado ao qual ela se refere, quando associada aos metadados e aos ambientes programáveis, tensiona a relação entre memória e imaginário, trazendo à tona o que se propõe denominar como lugares imaginários. Analisamos dois projetos, Sorting Daemons e Blackpool-Manchester, numa tentativa de elucidar como estas obras, cada uma à sua maneira, constrói tais lugares imaginários.
\end{abstract}

PALAVRAS-CHAVE: Memória, Metadados, Lugares imaginários, Ambientes programáveis, Arquivos.

O propósito desse artigo é verificar como as formas de registro e produção da memória, e um lugar no passado ao qual ela se refere, quando associadas aos metadados e aos ambientes programáveis, tensiona a relação entre memória e imaginário, trazendo à tona o que se propõe denominar como lugares imaginários. Já de início se faz necessário demarcar alguns conceitos que ajudarão a delinear prováveis respostas/provocações para pensar a conjunção aqui proposta: lugares imaginários. Paul Ricoeur (2007) propõe, logo no começo de "A memória, a história, o esquecimento", uma distinção entre memória (enquanto lembrança) e imaginação, a partir da noção de que a memória diria respeito a algo do passado, ainda que esteja ausente; a imaginação produziria também algo que está ausente, mas é ficcional, seria invenção. Obviamente, aqui operamos uma com uma versão resumida do argumento, procurando não diminuí-lo, mas com o intuito de potencializar a proposta de junção dos dois termos: memória e

\footnotetext{
"Universidade Federal de Minas Gerais. Professor Adjunto da Escola de Belas Artes. Imeio: chfalci@gmail.com.
}

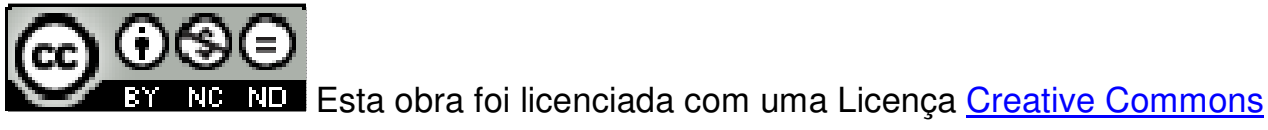

Texto Digital, Florianópolis, v. 9, n. 1, p. 213-226, jan./jul. 2013. ISSNe: 1807-9288 
invenção. A memória teria o caráter do algo acontecido, de um dado-presente no passado, e esse caráter seria uma função da narrativa. Aliamos a narrativa à memória nesse ponto, tomando a narrativa como uma configuração temporal. A apropriação aqui é também em torno das três mimeses de Ricoeur para caracterizar a narrativa.

A narrativa, segundo Ricoeur (1994), seria a forma de perceber o tempo, porque através dela o sujeito poderia experimentar o tempo pré-figurado, um tempo semelhante à temporalidade pura, ao se deparar com este mesmo tempo já configurado pela narrativa. Segundo o autor francês, a mimese deve ser compreendida em seu sentido dinâmico, como o processo ativo de representação do agenciamento dos fatos. Ou seja, a mimese produz a imitação da disposição dos fatos, da maneira de agenciá-los, a imitação da tessitura da intriga, que Aristóteles denomina muthos. Ricoeur sugere, entre mimese e muthos, uma ação criadora, em que a atividade mimética reproduz não uma ação, mas o modo com que essa ação pode se desenvolver. A mimese, base estrutural da narrativa, é uma ação de estruturar os fatos, mas ela começa com a disposição prática dos mesmos, tem continuidade com a percepção dessa disposição e termina com a leitura. Por isso Ricoeur instiga a pensar a mimese a partir do seu caráter de coerência. Trata-se de investigar, na relação entre as três mimeses, a forma do agenciamento dos fatos.

A mimese I é equivalente a um tempo pré-figurado, que será posteriormente configurado pela mimese II. Compreender mimese significa compreender a ação em geral pelos seus traços estruturais. É somente a partir dessa compreensão que se poderá operar, na mimese II, a configuração dessa mesma ação. Ou seja, se a tessitura da intriga é uma imitação da ação, é fundamental compreender quais são os traços componentes dessa ação. Ricoeur define três traços fundamentais da mimese I: os traços estruturais, os simbólicos e os temporais. Segundo o autor, toda ação possui traços estruturais relacionados aos agentes da ação, aos motivos da execução da ação e aos fins da ação. Entretanto,

Texto Digital, Florianópolis, v. 9, n. 1, p. 213-226, jan./jul. 2013. ISSNe: 1807-9288 
compreender esses traços é já ligá-los de alguma maneira, é possuir a competência do que se chama compreensão prática. A compreensão prática seria uma pré-compreensão narrativa, porque ligada à capacidade de acrescentar à estrutura prática da ação, ainda que minimamente, traços discursivos que ligariam logicamente os seus elementos. Para realizar a composição narrativa, seria preciso entender também as características simbólicas da ação. Ou seja, toda ação, se pode ser narrada, é porque já está articulada em signos, ou melhor, em símbolos. Aqui se encontram as características simbólicas da ação, que serão depois traduzidas na narrativa em termos de discurso. E, por fim, os traços temporais da ação estariam ligados ao ato de construir a ação como um todo, a partir da noção de tríplice presente em Santo Agostinho. A característica temporal da ação só seria percebida a partir de uma intratemporalidade, de uma construção do tempo da ação a partir de dentro da própria ação. Tais traços preparariam o sujeito para empreender a mimese II, a configuração da ação através da narrativa, a mediação da ação prática em direção à mimese III, que seria refiguração dessa mesma narrativa pelo leitor.

\begin{abstract}
Seguir uma história é avançar no meio de contingências e de peripécias sob a conduta de uma espera que encontra sua realização na conclusão. Essa conclusão não é logicamente implicada por algumas premissas anteriores. Ela dá à história um 'ponto final', o qual, por sua vez, fornece o ponto de vista do qual a história pode ser percebida como formando um todo (RICOEUR, 1994, p. 105).
\end{abstract}

A narrativa, nesse sentido, é menos a sequência de acontecimentos lineares e mais a configuração de um processo entre os acontecimentos que se encontravam ainda precariamente interligados em mimese I. A tal processo Ricoeur o denomina tessitura da intriga e, não, intriga. A noção de tessitura é empregada para enfatizar o caráter de mediação de mimese II, o seu caráter processual. É somente em mimese III que a narrativa permitiria compreender que o tempo percebido é sempre o tempo narrado, o tempo tornado humano na e com a narrativa.

Texto Digital, Florianópolis, v. 9, n. 1, p. 213-226, jan./jul. 2013. ISSNe: 1807-9288 
A mimese III é a ação que reconfigura o tempo pré-figurado da mimese I, através da experiência de mimese II. Tal reconfiguração não se dá apenas em função de uma suposta ordenação dos traços temporais que apareciam de maneira desordenada em mimese I. A configuração proposta em uma tessitura da intriga é apenas uma proposição e, como diz o próprio Paul Ricoeur, é o começo de um processo que encontra um termo em mimese III, e não necessariamente o seu término.

Quero aqui ficar com a questão da configuração temporal, o que seria a mimese II. Ela é entendida como uma trama que organiza um conjunto de elementos e confere a estes um lugar no passado, algo que teve lugar em algum momento. Aparece, desse modo, o primeiro conceito delineado nessa conversa: o lugar aqui é uma significância, ou melhor, uma representância de um evento passado. Nesse sentido, ele é uma construção narrativa, e uma configuração temporal. Quero, portanto, a partir dessa primeira demarcação, tentar verificar se metadados podem criar uma narrativa e, consequentemente, um lugar. Deixarei a discussão sobre o imaginário para um pouco mais adiante nesse texto.

Metadados podem ser considerados tanto uma descrição sobre um conjunto de dados quanto o seu modo de funcionamento num determinado contexto, considerando o modo como foram criados. (Manovich, 2002; Matthews, Aston, 2012). Por exemplo, quando uma tag como "Canon 550D" é adicionada a fotos no Flickr, esse metadado descreve o dado em si, mas já sugere um comportamento desse dados, pois indica que tal informação foi produzida por ou através de uma câmera fotográfica. E esse metadado faz com que o dado a ele associado seja incorporado a um conjunto similar de dados, com a mesma tag, através da lógica de funcionamento da interface utilizada. Podemos pensar em vários modos de incorporação; vou proceder aqui por analogia com o conceito de Ricoeur (1994) e sugerir que essa incorporação é um embrião de uma narrativa, algo que se situa no entre caminho da primeira e da segunda mimese. Seria o momento da compreensão prática, para tomarmos um termo utilizado de Ricoeur. Ou seja, o

Texto Digital, Florianópolis, v. 9, n. 1, p. 213-226, jan./jul. 2013. ISSNe: 1807-9288 
que a interface produz é uma configuração dos fatos, ainda que possamos questionar a ideia de tessitura que essa configuração carrega. Quando há uma apropriação de um conjunto de metadados numa organização arbitrária (ou seja, a partir de uma escolha), inicia-se a criação de um lugar, de uma marca temporal. Mas por que considera-lo dessa maneira? Porque ele é uma função dessa organização, que pode ser modificada a todo instante, de acordo com o ambiente em que os metadados estão funcionando. E, dentro da lógica da narrativa, ele apresenta os dados de maneira estruturada, diminuindo a sua vibração temporal. Há metadados que são construídos e disponibilizados para garantir uma maior estabilidade temporal da representância à qual se referem, enquanto outros talvez sejam mais fluidos. O movimento entre esses dois tipos de metadados é o que nos permitirá tratar dos lugares imaginários nesse texto.

O lugar criado pode, obviamente, apontar para um lugar físico, e adensar a materialidade desse ponto físico, criando camadas de memória relativas ao local em si. Tais camadas podem ser buscadas no conjunto de dados que um metadado específico permite acessar, como no caso da tag Canon 550D, no Flickr. $\mathrm{O}$ adensamento se daria pelo fato de que vários fatos passados, relativos ao local físico, podem ser agregados de maneira conjunta, ainda que sejam produzidos de maneira muito distinta, e com propósitos também distintos. Podemos conjugar tags como iphone e Chicago e visualizar um modo particular de registrar o que se considera ser a cidade de Chicago, vista através de iphones. O fato passado aqui é caracterizado pela ideia de que o registro é de um tempo que não é o atual, embora possa ser muito próximo do que acaba de acontecer. $\mathrm{E}$ seriam registros não ficcionais, uma vez que apontam para eventos que efetivamente tiveram um lugar no passado. A diferenciação em relação ao ficcional aqui é um tanto quanto instável, se tomarmos apenas a ideia de algo que foi inventado como sendo o terreno do ficcional. Tal instabilidade é também relativa ao fato de que os acontecimentos passados são escolhidos a partir de uma motivação, de uma pergunta ou questão que desejamos investigar. A motivação se refere a um procedimento destacado por Ricoeur (2007) ao tratar do

Texto Digital, Florianópolis, v. 9, n. 1, p. 213-226, jan./jul. 2013. ISSNe: 1807-9288 
método dos historiadores para abordar documentos que tratam do passado. Notese que o passado aqui é tomado como a garantia de um acontecimento que já teve lugar num tempo determinado, portanto, que existiu. Proponho, então, que possamos pensar essa prática dos historiadores como um procedimento comum a todos nós, para começarmos também a delinear uma poética dos metadados. Olha-se para acontecimentos passados e para os documentos que thes servem de comprovação a partir de uma questão que irá torna-los (os documentos) uma evidência do acontecimento que se deseja lembrar, do qual se deseja produzir memória. O que surge, doravante, como memória de um fato passado, é um conjunto de elementos que, mais do que apresentar efetivamente o passado, apresenta a maneira como esse passado foi construído. Ou melhor, a maneira como essa memória passa a re(a)presentar algo que é da ordem do passado. A memória teria uma dupla característica: ela faz o papel do acontecimento passado, e mostra a si mesma como construção de um fenômeno. Claro, ela pode pender mais para um dos lados dessa duplicidade, mas sempre esses dois componentes estarão presentes.

Seguindo a trilha de Paul Ricoeur (2007), mas também a discussão de Derrida (2001), um arquivo, ou os registros sobre um fato, são uma forma de testemunho que atestaria a existência passada do fato. A questão é que um testemunho já é uma organização particular, uma trama dos acontecimentos. Se o testemunho já é uma trama, ele fica no meio do caminho entre a invenção e a descoberta, o que exigiria uma aproximação capaz de isolar o modo como o testemunho foi criado. O uso do arquivo como prova documental teria essa capacidade, conquanto o arquivo pudesse ser analisado a partir de seus vários elementos mínimos constituintes (o ângulo em que uma foto foi realizada; quem fez a foto; o tipo de instrumento utilizado, a data e a hora em que a foto foi realizada etc). Esse procedimento conferiria objetividade, ou um maior grau de objetividade ao arquivo e, consequentemente, ao fato. Penso, no entanto, que a questão não é assim tão simples. Afinal, um arquivo, para garantir-se como evidência do lugar de um fato passado, de maneira inequívoca, deveria distanciar-se da trama que o criou?

Texto Digital, Florianópolis, v. 9, n. 1, p. 213-226, jan./jul. 2013. ISSNe: 1807-9288 
Deveria caminhar em direção de uma objetividade impossível? Essa seria a prova documental da memória por excelência? Mesmo aí se apresentam registros em escalas diferentes, obviamente. Além disso, quanto mais um arquivo parece se encaixar a contento em memórias distintas, mais central ele parece ser para uma memória que se afastaria da invenção, e se aproximaria da noção de descoberta. Esse é o movimento de reforçar a memória através do uso. Acontece que o uso da memória pode ensejar uma mistura diferente da anterior, tramando invenção e descoberta, não para igualá-las, mas para enfatizar o quanto a descoberta deve à possibilidade de invenção no uso dos arquivos. Potência essa que me parece ainda mais latente quando os metadados são apresentados em ambientes programáveis.

Os metadados são o que permitem que o computador recupere dados (falando em termos de ambientes programáveis), porque são o que permite que 0 computador "veja" os dados, além de realizar diversas outras tarefas, como mover os dados, comprimi-los etc (Manovich, 2002). Quero primeiro tomar o termo entre parênteses, esse reconhecimento dos dados através do "olhar" que o computador pode dar a eles. Ou seja, o computador estabelece algum tipo de relação com os dados através dos metadados. E trata-se de uma relação de reconhecimento, mas também de apropriação, de reconhecer uma certa autoridade sobre os dados, uma autoria sobre eles. O metadado carrega um pouco essa noção de autoria, ao que parece. E ela talvez possa ser pensada como algo compartilhado entre o instrumento que gera um conteúdo e o manipulador do instrumento. Será que podemos pensar num coletivo humano não-humano aqui, da forma como Latour (2001) caracteriza tais coletivos? Dependendo da forma como o metadado é organizado e colocado para funcionar numa determinada interface, ele é capaz de produzir essa noção de uma autoria compartilhada. O uso de uma hashtag, por exemplo, pode gerar um conjunto de imagens que remetem a um tema específico, a uma certa autoridade sobre o tema. 
Segundo Manovich, o paradigma de colocar metadados em imagens poderia levar a quatro direções: invenção de novos sistemas de descrição e categorização; invenção de novas interfaces para coleções de imagens; invenção de novos tipos de imagens que iriam além da denominação "vídeo digital" ou "still photograph"; criação de novas escalas de visualização "super humanas" a partir de dados disponíveis (imagens na web, registros de web cam etc). Manovich propõe a ideia de que uma imagem sozinha não é mais suficiente para produzir significado, ela só adquire significado dentro de um banco de dados muito mais vasto. Longe de concordar com essa noção, penso, entretanto, que a possibilidade de agregar imagens produzidas em momentos distintos, a partir de intencionalidades diferentes, é capaz de produzir outro olhar sobre essas imagens e uma outra relação, principalmente, com as lógicas que utilizamos para armazenar e organizar tais conteúdos. Aqui entraria a questão poética dos metadados. É o caso dos projetos This is now (<http://now.jit.su/>), e geoplay (<http://geoplay.info/>), por exemplo.

Formas narrativas em bancos de dados também se relacionam com um uso poético dos metadados. O que quero enfatizar, nesse aspecto, é como a lógica dos metadados pode ser utilizada de maneira narrativa, e assim criar efetivamente lugares imaginários, que são uma função derivada dessa narrativa, da interface, do comportamento dessa narrativa num ambiente programável. Assim, essa memória terminaria por ser um híbrido do modo de comportamento da interface, do conteúdo que podemos ver, e da materialização desse conteúdo em ambientes programáveis. Penso que essa materialização produz também uma memória, um rastro digital. Os metadados podem ser pensados como rastros, tanto na discussão de Ricoeur quanto na discussão de Fernanda Bruno. E esses rastros configurariam uma poética da memória em ambientes programáveis? Entendo que sim, mas é preciso compreender de que modo isso pode acontecer.

Em várias definições, como já indicado anteriormente, o metadado aparece como uma descrição de um dado. Quanto mais detalhada essa descrição, melhor seria 
a compreensão desse conteúdo a chance de recuperá-lo de maneira rápida e eficiente entre um conjunto vasto de arquivos. É como se o metadado permitisse isolar a trama que cria um documento, nos seus mínimos elementos constituintes. Um conjunto adequado de metadados seria um poderoso auxílio para estabilizar a autoridade de um documento, por exemplo, sobre o lugar de um fato no passado. Entretanto, essa visão do conjunto conveniente apresenta um aspecto problemático, uma vez que a ideia subjacente a essa adequação impediria usos diferentes dos metadados. E criaria uma noção autoritária sobre como construir e usar metadados, ao invés de uma noção autônoma do uso e criação desses elementos.

Pretende-se, então, verificar como os ambientes programáveis podem estimular uma poética dos metadados voltada para a responsabilidade mútua de criação de lugares imaginários. No modo poético a discussão recai sobre o que define um metadados e o seu modo de criação, e não sobre a maneira mais eficiente de fazer esse processo, somente. Não se parte de um pressuposto definido, mas sobre o que os metadados podem originar em termos de trama, de autoridade para um arquivo. Ou seja, parte-se do fenômeno que esses metadados podem disparar. E tal fenômeno é a construção de uma memória.

Por que esse tipo de ambiente é capaz de produzir lugares imaginários, associados então à noção de memória? Tomarei a noção de lugar, inicialmente, do lado da descoberta; o imaginário, por sua vez, ocupará o lado da invenção. Projetos que utilizam elementos descritivos de outros dados para apresentar a memória como um fato passado misturam esses dois conceitos porque os metadados tornam-se o elemento de criação da apresentação dessa memória. $\mathrm{E}$, mais que isso, são elementos modificáveis, ou que são testados em termos de sua capacidade de organização pela própria lógica que os produziu. Assim, a sua gênese enquanto metadado é definida pelo uso que o programa ou interface sugerem, em conjunto com a manipulação pelo coletivo de pessoas que também usa/produz a obra, mesmo sem se ligar a ela diretamente. Aqui entram em cena

Texto Digital, Florianópolis, v. 9, n. 1, p. 213-226, jan./jul. 2013. ISSNe: 1807-9288 
tanto o funcionamento das redes sócio técnicas quanto processos de individuação técnica que explicitam as ligações e tensões entre coletivos de humanos e nãohumanos. Isso significa defender que os metadados trabalham, no modo poético, de maneira equívoca, porque a prova documental que criam é transformada constantemente pelo ambiente programável.

Para verificar como esse movimento pode acontecer, tomo dois projetos que ficam no limite entre a invenção e a descoberta e, portanto, na lógica que delineio aqui, produzem lugares imaginários. Obviamente, em cada um deles há um equilíbrio instável que os faz pender mais para a invenção, ou mais para a descoberta.

O primeiro projeto se chama "Sorting Daemons", (<http://www.davidrokeby.com/sorting.html>) é de autoria de David Rokeby, e foi realizado numa primeira versão em 2003. A questão central aqui me parece ser 0 modo como uma câmera cria, a partir da delimitação de algumas coordenadas sobre como visualizar e separar conjuntos de elementos, uma interface em que as definições dos metadados se mostram capazes de inventar outros olhares sobre arquivos que documentam os elementos capturados pela câmera. O projeto de Rokeby se baseia em uma câmera, instalada numa galeria em Toronto (na versão de 2003), que captura imagens das ruas, buscando elementos moventes que possam ser considerados "pessoas". Quando ela reconhece algo que entender como uma pessoa, ela separa essa imagem do restante que foi capturado. Em seguida, a imagem extraída é dividida de acordo com áreas de cores similares, e as amostras de cor são projetadas num painel em LCD, de acordo com uma divisão arbitrária criada em consonância com o projeto artístico da obra.

A divisão opera separando os conjuntos de imagens de acordo com tonalidade, saturação e tamanho de cada imagem. A interface produz uma imagem abstrata que é baseada na capacidade que o programa tem de reconhecer cada metadado e sua relação com o que foi capturado pela câmera. É como se estivesse em 
funcionamento aqui a lógica da compreensão prática, que faz uma primeira interligação entre os dados, sem que essa tessitura esteja completa totalmente. Provoca-se o espectador, então, a não só perceber as imagens formadas, mas também o modo como a interface e os metadados constroem uma outra dinâmica de recuperação das imagens que passaram diante da câmera. Assim, o fato passado recobre-se tanto de invenção quanto de descoberta, e cada um desses termos reforça a presença do outro. Descoberta porque a câmera separa o que registrou e indica esse registro, antes da separação realizada pelos metadados. Invenção porque a interface provoca qualquer um que se depara com o painel da imagem projetada a olhar para sua própria memória, para sua ideia de memória e para o que câmera constrói enquanto memória. Aqui surge um dos lugares imaginários que defendo como tese desse artigo. O lugar é a imagem abstrata criada a partir dos arquivos separados pelos metadados. $O$ imaginário se situa próximo dessa invenção criada pelo programa que coloca a câmera e a separação das imagens em funcionamento. O lugar imaginário aparece enquanto fenômeno que aponta para si mesmo, para o seu modo de construção e para as suas diversas potências, uma vez que o que vemos como um fato passado, nesse caso, é somente uma configuração temporal do programa, da qual a imagem é apenas um dos modos de existência dessa memória.

O segundo projeto, intitulado "Blackpool, Manchester", (<http://www.nogovoyages.com/blackpool_manchester.html>) de autoria de Gwenola Wagon, trata mais especificamente da lógica de redes sócio técnicas na confluência com organizações de arquivos e metadados para funcionarem de maneira eficiente em tais redes. Aqui o modo poético cria uma apropriação que toma também os metadados como conjuntos narrativos equívocos e, portanto, abertos à invenção, produtores de lugares imaginários.

O projeto apresenta os trajetos que a criadora realiza ao se deslocar até a cidade de Blackpool, na Inglaterra e, posteriormente, até Manchester. Antes do deslocamento físico, Gwenola experimentou realizar uma viagem entre as duas 
cidades utilizando informações disponíveis em sites, utilizando dados do Google Earth ou mesmo do Second Life. Após fazer esse trajeto, ela viajou até Blackpool e fez um cruzamento entre as duas viagens, que é apresentando através de um vídeo com duas telas. Nessa apresentação, as referências se cruzam, e os terrenos se tornam provocações mútuas para reimaginar cada um dos lugares que a artista atravessou. A montagem, aqui, executa o papel de mostrar os lugares imaginários criados pela obra.

Um primeiro testemunho é trazido pelas viagens virtuais em que a artista explora arquivos organizados a partir de interfaces presentes em redes sócio técnicas, que apresentam assim sua própria trama, o seu modo de organizar um conjunto de informações sobre um local físico. Ainda que nos vídeos não nos seja possível visualizar os metadados que a artista utilizou para criar sua viagem, é possível perceber, pelo modo como o vídeo se desenvolve, que tais metadados permeiam a busca da viajante por informações sobre Blackpool, sobre Manchester, e sobre o trajeto entre as duas cidades. No entanto, é quando visualizamos o vídeo da artista já em Blackpool, juntamente com o vídeo das suas investigações nos arquivos em rede que fica claro como esse lugar imaginário é criado. Afinal, Gwenola refaz o trajeto que já havia feito virtualmente, em parte, e assim tensiona as duas narrativas, os dois conjuntos de arquivos que ela mesma produziu, em conjunto com interfaces programáveis. Ao visualizarmos as duas imagens, lado a lado, invenção e descoberta transitam entre as experiências, sem que seja possível definir de que lado cada um desses termos deve ficar definitivamente. A narrativa criada pela autora enfatiza esses deslocamentos, ao questionar, com a edição das imagens, o que é efetivamente um testemunho dos locais que visitou. Ela produz interferências nas imagens reais a partir de experiências que teve na web, buscando visualizar os locais físicos; e também reorganiza os trajetos virtuais ao experimentar os caminhos reais. Ainda que o vídeo nos apresente uma configuração temporal mais "fechada", a montagem quebra essa configuração, sugerindo que outras viagens poderiam estar contidas naquelas imagens. Ou seja, caso o banco de dados construído pela autora fosse reorganizado, ou os

Texto Digital, Florianópolis, v. 9, n. 1, p. 213-226, jan./jul. 2013. ISSNe: 1807-9288 
metadados fossem tramados de outra forma, os lugares aos quais eles se referem, obviamente, seriam distintos do que se vê. Mas, o que me parece aí mais fundamental é a explicitação de como esses dois arquivos terminam por se chocar, através do modo como a interface os organiza. Essa lógica de um ambiente programável para apresentar, de certa maneira, o processo de busca de arquivos é o que entendo como o surgimento da poética dos metadados.

Procurei, nesse artigo, apresentar projetos que mostram como o uso dos metadados é capaz de fazer surgirem lugares imaginários. Tais lugares são resultado do entrelaçamento entre invenção e descoberta, entre imaginação e memória. Defendo que a memória, ao ser criada em ambientes programáveis, confere outros usos à noção de arquivo, e força a uma revisão desse conceito, considerando os modos como os arquivos podem ser produzidos e recuperados com uso de metadados. $\mathrm{O}$ fato dos ambientes programáveis permitirem que a própria ação de criação e registro seja visualizada por quem consulta um arquivo de memória provoca-nos a pensar sobre a noção de autonomia e autoridade, e as possíveis relações entre esses termos. Por um lado, é possível entender e utilizar os metadados de maneira inequívoca, como se eles fossem capazes de estabelecer relações diretas e extremamente bem delimitadas entre 0 dado e 0 seu significado. Essa postura se basearia numa noção em que a autonomia para produzir a autoridade do arquivo se situaria fora do processo de tessitura coletiva de tais arquivos, ensejando, talvez, uma relação autoritária. De outro lado, o uso poético dos metadados aponta para a equivocalidade das relações como uma potência para que a autoridade dos arquivos seja derivada da autonomia que um coletivo de humanos e não-humanos pode ter ao fazer surgirem esses arquivos. Entre esses dois extremos situam-se os lugares imaginários, como a tensão necessária para que a dicotomia aqui proposta, a título provocativo, não seja solucionada por uma simples síntese entre os dois polos, ou por uma escolha de um dos dois. 


\section{IMAGINARY PLACES IN SOCIO-TECHNICAL NETWORKS: NARRATIVES OF MEMORY IN PROGRAMMABLE ENVIRONMENTS}

ABSTRACT: Does memory need a fixed place to exist? Does memory need archives to exist? And if it needs, what kind of files it needs? Although one can say that memory has never been defined from a fixed location, I think that the very definition of the concept is marked by idea of a place, a registry which is capable to show this memory. Even if it is related to the imaginary, or to instable elements, there is a tension associated with a search for a location to/for memory. The aim of this article is verify how this organization that produces memory, and a place in the past to which it refers, when associated to metadata and programmable environments, stress the relation between memory and imaginary, bringing to light what I'm calling imaginary places. We analyze two projects, Sorting Daemons and Blackpool-Manchester, seeking how these works, each in their own way, build this imaginary places.

KEYWORDS: Memory. Metadata. Imaginary places. Programmable environments. Archives.

\section{REFERÊNCIAS}

DERRIDA, Jacques. Mal de arquivo: uma impressão freudiana. Rio de Janeiro: Relume Dumará, 2001.

LATOUR, Bruno. Reagregando o social: uma introdução à teoria do Ator-Rede. Salvador: EDUFBA, 2012.

MANOVICH, Lev. Metadata, mon amour. 2002. Disponível em: <http://manovich.net>. Acesso em: 27 jun. 2013.

MATTHEWS, Paul; ASTON, Judith. Interactive multimedia ethnography: archiving workflow, interface aesthetics and metadata. In: ACM Journal on Computing and Cultural Heritage, v. 5, n. 4, 2012. p. 1-13.

RICOEUR, Paul. A memória, a história, o esquecimento. Campinas: Ed. da Unicamp, 2007.

Tempo e narrativa. Tomo 1. Campinas: Papirus, 1994.

Texto recebido em junho de 2013.

Texto Digital, Florianópolis, v. 9, n. 1, p. 213-226, jan./jul. 2013. ISSNe: 1807-9288 